\title{
Survival and life-expectancy in a young-onset dementia cohort with six years of follow-up
}

Citation for published version (APA):

Gerritsen, A. A. J., Bakker, C., Verhey, F. R., Pijnenburg, Y. A. L., Millenaar, J. K., de Vugt, M. E., \& Koopmans, R. T. C. M. (2019). Survival and life-expectancy in a young-onset dementia cohort with six years of follow-up: the NeedYD-study. International Psychogeriatrics, 31(12), 1781-1789.

https://doi.org/10.1017/S1041610219000152

Document status and date:

Published: 01/12/2019

DOI:

10.1017/S1041610219000152

Document Version:

Publisher's PDF, also known as Version of record

Document license:

Taverne

Please check the document version of this publication:

- A submitted manuscript is the version of the article upon submission and before peer-review. There can be important differences between the submitted version and the official published version of record.

People interested in the research are advised to contact the author for the final version of the publication, or visit the DOI to the publisher's website.

- The final author version and the galley proof are versions of the publication after peer review.

- The final published version features the final layout of the paper including the volume, issue and page numbers.

Link to publication

\footnotetext{
General rights rights.

- You may freely distribute the URL identifying the publication in the public portal. please follow below link for the End User Agreement:

www.umlib.nl/taverne-license

Take down policy

If you believe that this document breaches copyright please contact us at:

repository@maastrichtuniversity.nl

providing details and we will investigate your claim.
}

Copyright and moral rights for the publications made accessible in the public portal are retained by the authors and/or other copyright owners and it is a condition of accessing publications that users recognise and abide by the legal requirements associated with these

- Users may download and print one copy of any publication from the public portal for the purpose of private study or research.

- You may not further distribute the material or use it for any profit-making activity or commercial gain

If the publication is distributed under the terms of Article $25 \mathrm{fa}$ of the Dutch Copyright Act, indicated by the "Taverne" license above, 


\title{
Survival and life-expectancy in a young-onset dementia cohort with six years of follow-up: the NeedYD-study
}

\author{
Adrie A.J. Gerritsen, 1,2,3 Christian Bakker, 2,3,4 Frans R.J. Verhey, ${ }^{5}$ \\ Yolande A.L. Pijnenburg, ${ }^{6}$ Joany K. Millenaar, ${ }^{5}$ Marjolein E. de Vugt ${ }^{5}$ \\ and Raymond T.C.M. Koopmans $2,3,7$ \\ ${ }^{1}$ De Wever, Centre for Elderly Care, Tilburg, the Netherlands \\ ${ }^{2}$ Department of Primary and Community Care, Radboud University Medical Centre, Radboud Institute for Health Sciences, Nijmegen, the Netherlands \\ ${ }^{3}$ Radboud University Medical Centre, Alzheimer Centre, Nijmegen, the Netherlands \\ ${ }^{4}$ Florence, Mariahoeve, Centre for Specialized Care in Young-onset Dementia, Den Haag, the Netherlands \\ ${ }^{5}$ School for Mental Health and Neuroscience, Alzheimer Centre Limburg, Maastricht University Medical Centre, Maastricht, the Netherlands \\ ${ }^{6}$ Department of Neurology and Alzheimer Centre, Amsterdam University Medical Centres, Amsterdam Neuroscience, Amsterdam, the Netherlands \\ ${ }^{7}$ Foachim en Anna, Centre for Specialized Geriatric Care, Nijmegen, the Netherlands
}

Objectives: The aim of this study was to investigate survival time and life-expectancy in people with young-onset dementia (YOD) and to examine the relationship with age, sex, dementia subtype and comorbidity.

Design, Setting and Participants: Survival was examined in 198 participants in the Needs in Young-onset Dementia study, including participants with Alzheimer's dementia (AD), vascular dementia (VaD) and frontotemporal dementia (FTD).

Measures: The primary outcomes were survival time after symptom onset and after date of diagnosis. Cox proportional hazards models were used to explore the relationship between survival and age, sex, dementia subtype and comorbidity. Additionally, the impact on remaining life expectancy was explored.

Results: During the six-year follow-up, 77 of the participants died (38.9\%), 78 participants survived (39.4\%) and 43 were lost to follow-up (21.7\%). The mean survival time after symptom onset and diagnosis was 209 months (95\% CI 185-233) and 120 months (95\% CI 110-130) respectively. Participants with AD had a statistically significant shorter survival compared with $\mathrm{VaD}$ participants, both regarding survival after symptom onset $(p=0.047)$ as well as regarding survival after diagnosis $(p=0.049)$. Younger age at symptom onset or at diagnosis was associated with longer survival times. The remaining life expectancy, after diagnosis, was reduced with $51 \%$ for males and $59 \%$ for females compared to the life expectancy of the general population in the same age groups.

Conclusion/Implications: It is important to consider the dementia subtype when persons with YOD and their families are informed about the prognosis of survival. Our study suggests longer survival times compared to other studies on YOD, and survival is prolonged compared to studies on LOD. Younger age at symptom onset or at diagnosis was positively related to survival but diagnosis at younger ages, nevertheless, still diminishes life expectancy dramatically.

Key words: Young Onset Dementia, Dementia, Long-Term Care

\section{Introduction}

Between $2 \%$ and $10 \%$ of the approximately 9.9 million persons who are annually diagnosed with

\footnotetext{
Correspondence should be addressed to: Adrie A.J. Gerritsen, MD, Department of Primary and Community Care, Radboud University Medical Centre, code 117 ELG, PO Box 9101, 6500 HB Nijmegen, the Netherlands. Phone: + 31 (0)13 4644166, Fax: + 31 (0)13 4644433. Email: adrie.gerritsen@radboudumc.nl. Received 14 Oct 2018; revision requested 31 Oct 2018; revised version received 16 Jan 2019; accepted 17 Jan 2019. First published online 27 March 2019.
}

dementia worldwide, experience their first symptoms before the age of 65 years; this is, so-called young-onset dementia (YOD) (Carter et al., 2018; Prince, et al., 2016; World-Health-Organization, 2012). Better insight into survival time and associated characteristics is necessary to improve our understanding of young-onset neurodegenerative diseases, and for planning specific services. Knowledge can be increased by gaining more insight into the differences in survival regarding the different 
causes of YOD, in particular for the three most common dementia subtypes in YOD. Furthermore, besides age and gender, also the potential influence of comorbidity should not be underestimated even in younger individuals, but this has not been considered in earlier studies on YOD.

There is no consensus in literature that YOD has a more progressive disease course resulting in shorter survival compared to late-onset dementia (LOD) (onset > 65 years) (Barclay et al., 1985b; DiehlSchmid et al., 2007; Gerritsen et al., 2018; Gronning et al., 2012; Jacobs et al., 1994; Koedam et al., 2008; Panegyres and Chen, 2013; Stanley and Walker, 2014; van der Vlies et al., 2009). Younger age has been found to be negatively associated with survival in Alzheimer's dementia (AD) and frontotemporal dementia (FTD) studies (Barclay et al., 1985a; Diehl-Schmid et al., 2007). However, despite the higher mortality risk in YOD found by Koedam et al. (2008), survival of YOD participants was longer compared with LOD (Koedam et al., 2008). Furthermore, male sex in YOD is not consistently associated with shorter survival, while comorbidity shows a more consistent negative relationship with survival in YOD (Armstrong, 2014; Barclay et al., 1985b; Brodaty et al., 2012; Kay et al., 2000). In the review of Brodaty et al. (2012), men and women showed the same life expectancy, but in this comparison no distinction was made between those with YOD and LOD (Brodaty et al., 2012).

Knowing the characteristics that are related to survival in YOD can help in providing a prognosis, and in reducing feelings of uncertainty after diagnosis (Stokes et al., 2015). The aim of this longitudinal cohort study was to investigate the survival time of people with YOD from both disease onset and date of diagnosis and the association of YOD with age at onset or diagnosis, gender, dementia subtype and comorbidity. Furthermore, we investigated the impact of the diagnosis of YOD on life expectancy.

\section{Methods}

\section{Study design and selection of participants}

Participants were selected from the Needs in Youngonset Dementia (NeedYD) study, which has been described previously (van Vliet et al., 2010). Participants were recruited from university medical centres, regional hospitals, mental health services and specialized Dutch day-care facilities. Only participants with $\mathrm{AD}$, Vascular dementia $(\mathrm{VaD}) /$ mixed dementia and FTD were included in this study. Dementia subtypes were established according to regular criteria and the consensus on clinical dementia subtypes (Erkinjuntti, 1994; McKhann et al., 1984; Neary et al., 1998). The study protocol was approved by the Medical Ethics Committee of the University Medical Center, Maastricht. The local ethics committees of the participating institutions also gave consent. The research study was performed according to the principles of the Declaration of Helsinki (version January 2004; www.wma.net) and is in agreement with the law regarding medical-scientific research in humans (WMO). Data collection, after written informed consent was obtained, started in 2007 and 2008 (baseline). Information about the study was provided by the memory clinics or day-care facilities, and then again by the researcher. Participants who were not able to sign informed consent were asked to give oral consent and also their legal representative was asked to give written consent. This was followed by assessments at six-month intervals for two years and then at three, four and six years after inclusion.

\section{Primary outcomes}

Survival from symptom onset and survival from date of diagnosis were calculated in months. Using a semistructured open-ended interview, the primary caregivers were asked for the date of the earliest signs or symptoms. Then, they were asked to elaborate on their answers and identify if there were any earlier signs or symptoms. The date of the earliest signs or symptoms, cognitive, behavioural or functional, was recorded as the date of symptom onset. Date of dementia was retrieved from the participants' medical records. The date of symptom onset was set at January first in the year of onset if the exact date was not known by the primary caregiver. For both outcomes, survival time was calculated from date of symptom onset or date of diagnosis to date of death or date of censoring (date of the last contact with the participant or caregiver is used in the analysis, at that time participant is still alive) during the six-year follow up.

\section{Determinants}

Dementia subtype was established according to the criteria of McKhann, the NINDS-AIREN criteria, the consensus on clinical diagnostic criteria of FTD and the consensus on clinical dementia subtypes (Erkinjuntti, 1994; First et al., 2002; McKhann et al., 1984; Neary et al., 1998). Age at symptom onset and age at diagnosis were calculated in years from date of birth and date at symptom onset or date at diagnosis, respectively. Comorbidity was registered at baseline using the participants' medical records and structured interviews with the primary caregiver. Comorbidity was classified by the first author (AG), using the International Classification of Diseases, 10th Revision (ICD-10) (World Health Organization). The ICD-10 classifies diseases in 
Table 1. Baseline findings

\begin{tabular}{|c|c|c|c|c|c|}
\hline & $\begin{array}{c}\text { ALL } \\
(N=198)\end{array}$ & $\mathrm{AD}(N=122)$ & $\operatorname{vaD}(N=34)$ & $\operatorname{FTD}(N=42)$ & TEST $^{*}$ \\
\hline Male (\%) & $105(53.0)$ & $57(46.7)$ & $22(64.7)$ & $26(61.9)$ & $\begin{array}{c}\chi^{2}(\mathrm{df} 2)=5.318 \\
\mathrm{p}=0.08\end{array}$ \\
\hline $\begin{array}{l}\text { Mean age at inclusion } \\
\text { (SD) [range] }\end{array}$ & $\begin{array}{c}61.4(5.5) \\
{[43.4-74.7]}\end{array}$ & $\begin{array}{c}61.5(4.9) \\
{[48.6-73.5]}\end{array}$ & $\begin{array}{c}61.2(5.3) \\
{[46.4-69.6]}\end{array}$ & $\begin{array}{l}61.4 .4(7.3) \\
{[43.4-74.7]}\end{array}$ & $\begin{array}{c}\mathrm{F}(2,198)=0.38 \\
\mathrm{p}=0.96\end{array}$ \\
\hline $\begin{array}{l}\text { Mean age at diagnosis } \\
\text { (SD) }[\mathrm{N}]\end{array}$ & $58.7(5.5)[197]$ & $58.9(5.0)[122]$ & $58.1(5.2)[34]$ & $58.5(7.2)[41]$ & $\begin{array}{c}\mathrm{F}(2,196)=0.241 \\
\mathrm{p}=0.79\end{array}$ \\
\hline $\begin{array}{l}\text { Mean age at symptom } \\
\text { onset (SD) }[\mathrm{N}]\end{array}$ & $54.3(6.5)[197]$ & $54.5(5.5)[121]$ & $53.2(6.7)[34]$ & $54.7(8.6)[42]$ & $\begin{array}{c}\mathrm{F}(2,196)=0.594 \\
\mathrm{p}=0.55\end{array}$ \\
\hline $\begin{array}{l}\text { Time in months between } \\
\text { symptom onset and } \\
\text { diagnosis (SD) }[\mathrm{N}]\end{array}$ & $53(44)[196]$ & $52(45)[121]$ & 59 (46) [34] & 49 (39) [41] & $\begin{array}{c}\mathrm{F}(2,195)=0.491 \\
\mathrm{p}=0.61\end{array}$ \\
\hline Mean GDS (SD) $[\mathrm{N}]$ & $4.4(1.1)[188]$ & $4.7(1.0)[118]$ & $3.9(1.0)[31]$ & $4.1(1.3)[39]$ & $\begin{array}{c}\chi^{2}(\mathrm{df} 10)=30.189 \\
\mathrm{p}=0.001^{* *}\end{array}$ \\
\hline Comorbidity N (\%) & $95(48.0)$ & $53(43.4)$ & $18(52.9)$ & $24(57.1)$ & $\begin{array}{c}\chi^{2}(\mathrm{df} 2)=2.754 \\
\quad \mathrm{p}=0.25\end{array}$ \\
\hline
\end{tabular}

$\mathrm{AD}$ : Alzheimer's dementia, VaD: vascular dementia including mixed $\mathrm{AD} / \mathrm{VaD}, \mathrm{FTD}$ : frontotemporal dementia.

*Comparison among diagnosis groups, $\chi^{2}$ or F-test (ANOVA),

**Significant difference among $\mathrm{AD}$ and $\mathrm{VaD}, \mathrm{FTD}$.

categories, with sub-categories to describe specific diseases. For the current study, classification was performed at the sub-category level, or, if the information was not specific enough, at the category level.

\section{Demographic characteristics}

Sex, date of birth, and date of death were collected through structured interviews with primary caregivers. Dementia severity at baseline was assessed using the Global Deterioration Scale (GDS), which rates dementia severity from "no impairment" (GDS stage 1) to "very severe cognitive impairment" (GDS stage 7) (Reisberg et al., 1982).

\section{Statistical analysis}

The analyses were performed using the Statistical Package for Social Sciences (SPSS), version 22.2.0.01 (2013), (IBM SPSS Statistics, IBM Corporation, Chicago, IL). Proportions and means were calculated to describe characteristics of the participants. Group comparisons regarding dementia subtypes ( $\mathrm{AD}, \mathrm{VaD}, \mathrm{FTD})$ were analysed using analysis of variance (ANOVA) for continuous variables or chi-squared tests and log-rank tests for categorical variables. Survival analyses were performed with the Kaplan-Meijer estimator (Kaplan and Meier, 1958). Cox proportional hazards $(\mathrm{CPH})$ models were used to relate age at symptom onset or age at diagnosis, sex, dementia subtype and comorbidity with survival (Breslow, 1974; Crowley and Breslow, 1984). A subanalysis on age at symptom onset or diagnosis was performed to see if there were differences between the diagnoses. Comorbidity was classified "yes" when one or more comorbid conditions were present; otherwise, classification was "no." A t-test was used in a sensitivity analysis whether or not to consider left truncation. Left truncation means that a correction may be needed for potential participants who did not survive until the date of inclusion, and, thus, did not enter the study population, resulting in possible overestimation of survival (Addona et al., 2012; Vansteelandt et al., 2017). For this sensitivity analysis, the study population was divided into two groups, one with the participants who had the longest baseline survival time from symptom onset and one with the shortest. The two groups were compared considering the survival time during the six-year follow-up. A similar sensitivity analysis was performed for the groups with the longest and shortest baseline survival times from date of diagnosis. The relative loss of remaining life expectancy was calculated in percentages by dividing the years of life lost after diagnosis by the matched life expectancy in the Dutch general population aged 61 in 2007 (Statline, 2017a).

For all analyses, a P-value $<0.05$ was used as the threshold for statistical significance.

\section{Results}

A total of 198 participants were included, 122 with $\mathrm{AD}, 34$ with $\mathrm{VaD} /$ mixed dementia, and 42 with FTD (van Vliet et al., 2010). The mean age at diagnosis was 58.6 (SD 5.5) years and median time from diagnosis until inclusion was 2.2 years (IQR 0.9-4.0). There were slightly more male than female participants (Table 1). 
Table 2. Survival in months

\begin{tabular}{|c|c|c|c|c|c|}
\hline & ALL $(N=198)$ & $\mathrm{AD}(N=122)^{*}$ & $\operatorname{vaD}(N=34)$ & $\operatorname{FTD}(N=42)^{*}$ & TEST $^{* *}$ \\
\hline \multicolumn{6}{|l|}{ After diagnosis } \\
\hline mean (SD) & $120(5.0)$ & $111(5.8)$ & $142(11.7)$ & $120(9.9)$ & $\chi^{2}(\mathrm{df} 2)=8.064$ \\
\hline$[95 \% \mathrm{CI}]$ & [110-130] & {$[100-123]$} & [119-165] & {$[101-140]$} & $\mathrm{p}=0.018$ \\
\hline median $[95 \% \mathrm{CI}]$ & $112[101-123]$ & $103[88-119]$ & $179^{* * *}$ & $135[111-158]$ & \\
\hline \multicolumn{6}{|c|}{ After symptom onset } \\
\hline mean $(\mathrm{SD})$ & $209(12.1)$ & $187(13.2)$ & $270(29.5)$ & $197(12.6)$ & $\chi^{2}(\mathrm{df} 2)=7.511$ \\
\hline$[95 \% \mathrm{CI}]$ & [185-233] & {$[161-213]$} & {$[212-327]$} & [172-221] & $\mathrm{p}=0.023$ \\
\hline median $[95 \% \mathrm{CI}]$ & 194 [139-249] & $156[128-184]$ & & $245^{* * *}$ & \\
\hline
\end{tabular}

AD: Alzheimer's dementia, VaD: vascular dementia including mixed dementia, FTD: frontotemporal dementia. * One missing value on FTD date of diagnosis, one missing value on $\mathrm{AD}$ date of symptom onset.

** Comparison among diagnosis groups,

$* * *$ Too many survivors to calculate $95 \% \mathrm{CI}$,

****Too many survivors to calculate median.

Table 3. Cox proportional hazard ratios

\begin{tabular}{|c|c|c|c|c|c|c|c|c|}
\hline & \multicolumn{8}{|c|}{ SURVIVAL AFTER SYMPTOM ONSET } \\
\hline & \multirow[t]{2}{*}{ B } & \multirow[t]{2}{*}{ SE } & \multirow[t]{2}{*}{ WALD } & \multirow[t]{2}{*}{ DF } & \multirow[t]{2}{*}{ SIG. } & \multirow[t]{2}{*}{$\operatorname{EXP}(\mathrm{B})$} & \multicolumn{2}{|c|}{$\begin{array}{c}95.0 \% \text { CI FOR } \\
\operatorname{EXP}(\mathrm{B})\end{array}$} \\
\hline & & & & & & & LOWER & UPPER \\
\hline Dementia subtype & & & 6.271 & 2 & .043 & & & \\
\hline Alzheimer's dementia & .771 & .387 & 3.960 & 1 & 0.047 & 2.162 & 1.012 & 4.618 \\
\hline $\begin{array}{l}\text { Frontotemporal dementia } \\
\text { Vascular dementia }{ }^{*} \text { (ref) }\end{array}$ & .141 & .466 & .092 & 1 & .762 & 1.152 & .462 & 2.871 \\
\hline Gender & -.060 & .241 & .063 & 1 & .80 & .941 & .587 & 1.511 \\
\hline Comorbidity (yes/no) & .281 & .231 & 1.470 & 1 & .23 & 1.324 & .841 & 2.084 \\
\hline Age at symptom onset & .133 & .023 & 32.641 & 1 & $<.001$ & 1.142 & 1.091 & 1.196 \\
\hline Alzheimer's dementia & .137 & .029 & 22.284 & 1 & $<.001$ & 1.147 & 1.084 & 1.215 \\
\hline Vascular dementia* & .164 & .079 & 4.284 & 1 & .04 & 1.178 & 1.009 & 1.375 \\
\hline Frontotemporal dementia & .149 & .057 & 6.795 & 1 & .009 & 1.161 & 1.038 & 1.298 \\
\hline
\end{tabular}

*Vascular dementia including vascular/mixed Alzheimer's dementia (-2 log likelihood 654.884), p < 0001.

\section{Survival}

During the six-year follow-up, 77 of the participants died $(38.9 \%), 78$ participants survived $(39.4 \%)$ and 43 were lost to follow-up (21.7\%). Kaplan-Meijer analysis showed a mean survival time from symptom onset of 209 months (95\% CI 185-233) and a mean survival time after diagnosis of 120 months $(95 \%$ CI 110-130) (Table 2). This corresponds with 17 years and 5 months and 10 years, respectively. In 2007, at the time of the first assessment in our study, general life expectancy in healthy adults at age 60 in the Netherlands was 21.4 years in males and 25.2 years in females (Statline, 2017a). The expected loss of life years found in this study is approximately 11 years for male participants and approximately 15 years for female participants. The relative loss of remaining life expectancy after diagnosis was $52 \%$ in male participants and $61 \%$ in female participants, compared to the life expectancy of the general population in the same age groups.

\section{Determinants of survival}

A diagnosis of $\mathrm{AD}$ decreased the likelihood of survival by 2.16 times compared with a $\mathrm{VaD}$ diagnosis (Table 3, Figure 1). We also found a trend of a decreased survival for the participants with $\mathrm{AD}$ compared with FTD participants. The same association between dementia subtypes and survival from the date of diagnosis was found (Table 4, Figure 1).

Age at symptom onset also showed an association with survival. The likelihood of a shorter survival increased $14 \%$ with each additional year of age at symptom onset (Table 3). This likelihood of a shorter survival was found in all three dementia subtypes (Table 3). In the CPH model of survival from date of diagnosis, a similar relationship between age at diagnosis and survival was found, with an almost $7 \%$ higher chance of a shorter survival with each extra year of age at the time of diagnosis (Table 4). In the sub analysis, however, statistical significance only was seen for $\mathrm{AD}$ and FTD subtypes. 


\begin{tabular}{|c|c|c|c|c|c|c|c|c|}
\hline & \multicolumn{8}{|c|}{ SURVIVAL AFTER DIAGNOSIS } \\
\hline & \multirow[t]{2}{*}{ B } & \multirow[t]{2}{*}{ SE } & \multirow[t]{2}{*}{ WALD } & \multirow[t]{2}{*}{ DF } & \multirow[t]{2}{*}{ SIG. } & \multirow[t]{2}{*}{$\operatorname{EXP}(B)$} & \multicolumn{2}{|c|}{$\begin{array}{c}95.0 \% \text { CI FOR } \\
\operatorname{EXP}(\mathrm{B})\end{array}$} \\
\hline & & & & & & & LOWER & UPPER \\
\hline Dementia subtype & & & 6.091 & 2 & .048 & & & \\
\hline Alzheimer's dementia & .761 & .386 & 3.887 & 1 & .049 & 2.140 & 1.004 & 4.559 \\
\hline Frontotemporal dementia & .161 & .463 & .122 & 1 & .727 & 1.175 & .475 & 2.909 \\
\hline \multicolumn{9}{|l|}{ Vascular dementia* $^{*}$ (ref) } \\
\hline Gender & .020 & .237 & .007 & 1 & .93 & 1.021 & .642 & 1.623 \\
\hline Comorbidity (yes/no) & .126 & .245 & .264 & 1 & .61 & 1.134 & .702 & 1.831 \\
\hline Age at symptom onset & .067 & .021 & 9.940 & 1 & .002 & 1.069 & 1.026 & 1.115 \\
\hline Alzheimer's dementia & .082 & .034 & 5.943 & 1 & .015 & 1.085 & 1.016 & 1.154 \\
\hline Vascular dementia ${ }^{*}$ & .071 & .082 & .0762 & 1 & .38 & 1.074 & .915 & 1.261 \\
\hline Frontotemporal dementia & .156 & .058 & 7.347 & 1 & .007 & 1.169 & 1.044 & 1.308 \\
\hline
\end{tabular}

*Vascular dementia including vascular/mixed Alzheimer's dementia (-2 Log Likelihood 677.183), p=0.004.

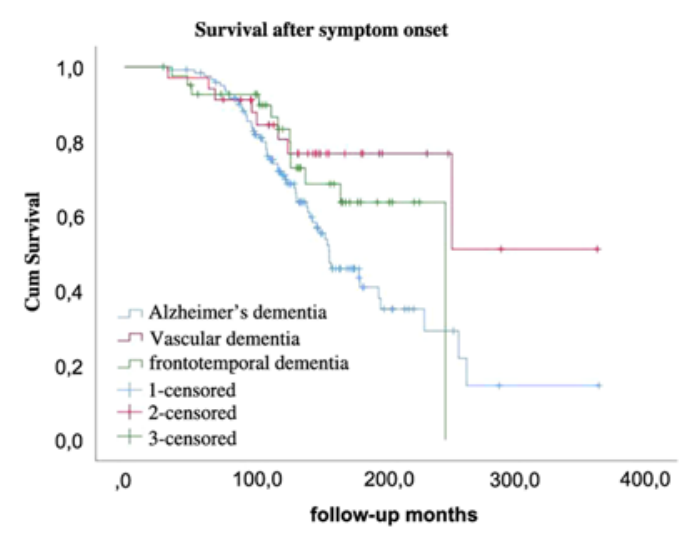

Figure 1. Survival.

No association was found between survival and sex, or having comorbid conditions in either $\mathrm{CPH}$ models.

The sensitivity analysis concerning left truncation revealed no significant difference in survival time during the six-year follow up. The mean difference was 0.4 months between the group with the longest versus shortest baseline survival time of diagnosis $(\mathrm{p}=0.884)$. For symptom onset, the mean difference was 0.1 months in the six-year follow up $(\mathrm{p}=0.965)$.

\section{Discussion}

The survival from date of diagnosis found in our study was substantially less than the general life expectancy in the Netherlands (Statline, 2017a). Furthermore, survival times after symptom onset and after diagnosis were associated with dementia subtypes but not with comorbidity or with sex.

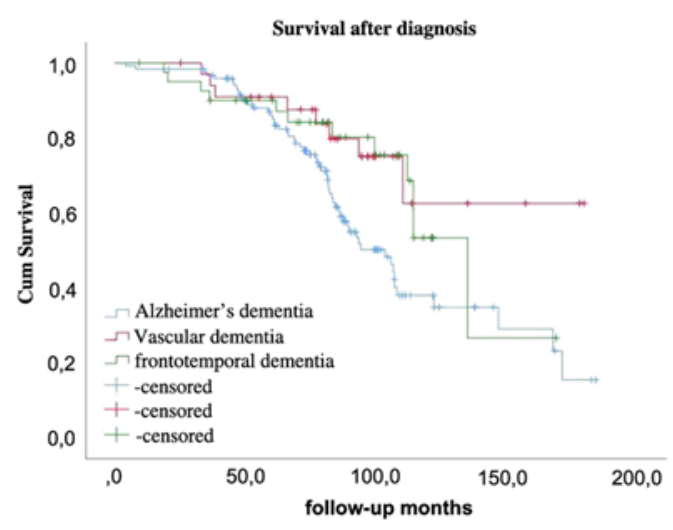

The relative loss of more than $50 \%$ of remaining life expectancy that we found is lower than in a review by Brodaty et al. (2012) who calculated percentages of $60-94 \%$ in YOD populations (Brodaty et al., 2012). This lower loss of remaining life expectancy is in line with the longer survival times we found, but the outcome for these young persons with dementia is dramatic. Furthermore, in that review more dementia subtypes were included compared to our study, among which FTD with motor neuron disease, which also can contribute to the differences we found on the relative loss of remaining life expectancy.

The survival time after symptom onset found in our study was prolonged by about five years compared with findings in other studies (Brodaty et al., 2012; Todd et al., 2013). However, none of the study populations included in those reviews are comparable with our population. Todd et al. (2013) investigated survival after symptom onset in a review of 
studies in dementia, in general, not specifically in YOD (Todd et al., 2013). In a review by Brodaty et al. (2012), ten studies reported on survival in YOD, of which five on YOD specifically, and two of them reported on survival after symptom onset (Jost and Grossberg, 1995; McGonigal et al., 1992). Median survival times from symptom onset reported in those two studies ranged from 5.8-10.8 years, while in our study this was 9.3 years. The study populations in those two studies are from before 1995; after this time, survival in the general population, and likely also in persons with YOD, has increased because of less mortality due to cardiovascular disease and cancer (Milieu, 2018). Furthermore, we thoroughly investigated the date of first symptoms.

Mean survival after diagnosis in our study is approximately two years longer than the longest survival time (7.9 years) reported in a review of Brodaty et al. (2012) (Brodaty et al., 2012). In two studies investigating survival after diagnosis, median survival times ranged from approximately 3.4 to 6 years in young participants. The study populations of those two studies differed from our population. One study included $\mathrm{AD}$ and $\mathrm{VaD}$, while we also included FTD. The other study examined survival times regardless of dementia subtype (Kay et al., 2000; Koedam et al., 2008). We know that the time needed to establish a diagnosis of YOD, and accuracy has been improved during the 20 years between the start of the study of Kay et al. (2000) and the start of our study, due to improved structural behavioural and psychiatric assessments, neuroimaging and the examination of cerebrospinal fluid (Kay et al., 2000; Rossor et al., 2010). This likely resulted in an earlier diagnosis in our cohort and, consequentially, a longer survival after diagnosis.

We found an association of dementia subtypes with survival in which $\mathrm{AD}$ participants had lower survival rates compared to VaD participants. This seems in contrast with the results of other studies that found an equal or longer survival in $\mathrm{AD}$ subtypes compared with $\mathrm{VaD}$ (Kay et al., 2000; Koedam et al., 2008). However, again, these figures are from populations that show some important differences from our study population. Kay et al. (2000) only compared $\mathrm{AD}$ and $\mathrm{VaD}$, and Koedam et al. (2008) made a comparison of all the study participants (young and elderly) with a control group of participants without dementia (Kay et al., 2000; Koedam et al., 2008).

Having a diagnosis or symptoms of dementia at a younger age resulted in this study in higher survival rates, which has also been found by others, who found longer survival times in younger YOD persons (Jost and Grossberg, 1995; Knopman et al., 2003). Within a young-onset Alzheimer's dementia (YO-AD) study population, the opposite was found; younger $\mathrm{AD}$ participants showed higher mortality rates in comparison with those who were older at the time of diagnosis, and some studies found no association of age with survival (Kay et al., 2000; McGonigal et al., 1992; Ueki et al., 2001). We found no YOD studies investigating the association of age with survival, in which, survival analysis were performed correcting for dementia subtypes (Hodges et al., 2003; Knopman et al., 2003; Rait et al., 2010; Roberson et al., 2005). It is known that in LO-AD, younger age is related to shorter survival. We found the opposite for all dementia subtypes. We do know that comorbidity in YO-AD is less compared to $\mathrm{LO}-\mathrm{AD}$; however, we included comorbidity in the statistical model to correct for this factor. We found the opposite for all dementia subtypes. We do know that comorbidity in YO-AD is less compared to $\mathrm{LO}-\mathrm{AD}$, but we corrected for comorbidity when we found this outcome (Gerritsen et al., 2016; Hodges et al., 2003; Holland et al., 2012; Knopman et al., 2003; Perrault et al., 2002; Rait et al., 2010; Rasmusson et al., 1996; Roberson et al., 2005; Stanley and Walker, 2014). Therefore, the finding that the youngest participants showed the longest surviva, might be due to their better physical condition in comparison to the older YOD participants.

For age at symptom onset, all three dementia subtypes showed an association with longer survival when symptoms arose earlier, but for age at diagnosis, the subanalysis showed no statistical significance for the $\mathrm{VaD}$ participants (Tables 3 and 4).

No association has been found between survival and the presence (or lack) of comorbidity. We found only one study on YO-AD investigating this association between comorbidity and survival (Ueki et al., 2001). In that study, concurrent physical illness was found to negatively influence survival, but our analysis did not show this outcome. The findings of our study might suggest that persons with YOD have a disease trajectory that is less affected by comorbidity compared with LOD, as was also found in a study on YO-AD (Chang et al., 2017). Furthermore, it is likely that frailty, including the burden of comorbidity, might be a more important risk factor of mortality in LOD than comorbidity (Kane et al., 2012).

Sex showed no association with survival in our study, and it remains unclear why this finding differs from many LOD studies in which male sex has been found to be associated with shorter survival (GarciaPtacek et al., 2014; Ientile et al., 2013; Lee and Chodosh, 2009). However, in the review of Brodaty et al. (2012) men and women showed the same life expectancy taking no account for the categories YOD and LOD (Brodaty et al., 2012). The a priori chance of dying before 2016, when aged 61 in 2007, in the Netherlands was less than $2 \%$ in males and 
less than $1.5 \%$ in females. Therefore, dementia, and not sex, is more likely the main cause of the limited survival at this age (Statline, 2017b).

\section{Limitations and strengths}

There are some limitations in this study that have to be considered. First, by setting January first as the date of symptom onset when the exact date was not available, survival could be prolonged six months, on average. However, knowing that there were 77 survivors means that survival time will be longer when we would have been able to extend our followup period beyond six years. Of course, it is difficult for caregivers to give an exact date of symptom onset, because dementia often has an insidious onset. This can result in a possible under- or overestimation of survival time after symptom onset. However, this is inherent to the study design. Second, we were not able to include disease severity at diagnosis in the $\mathrm{CPH}$ models because this information was not available. There are some indications that disease severity at diagnosis shows a relationship with survival; however, not all studies found this relationship (Atkins et al., 2012; Ientile et al., 2013; Todd et al., 2013; Tschanz et al., 2004). Third, $21.7 \%$ of the participants were lost during our six-year follow-up and $39.4 \%$ survived. We think losing participants is inherent for long lasting cohort studies. The chosen statistical analysis, Kaplan-Meijer, can address this loss and surviving participants; however, outcomes remain estimates until all participants are deceased. Fourth, unfortunately, we had no access to the death certificates to examine the causes of death. This would be helpful as in a study on survival, information about causes of death is informative for both families and clinicians. However, our study did reveal survival times for the three most common subtypes of dementia in YOD and showed that comorbidity was not related to survival. Fifth, we did not have information on the severity of the comorbid conditions, which would have been interesting to take into account. Also, we had no information on intercurrent diseases such as pneumonia which could have influenced survival. However, studying the relationship of comorbidity and survival in YOD, is a reasonably unexplored topic.

The strength of our study is the sensitivity analysis we did on left truncation. Cohort studies are frequently influenced because some potential participants do not enter the study because they pass away before the date of inclusion, which is considered left truncation (Addona et al., 2012; Vansteelandt et al., 2017). However, we found that survival time after the date of diagnosis in our cohort was not influenced due to this effect, and this was confirmed with the sensitivity analysis.

\section{Conclusion/Relevance}

Our study outcomes add information to the knowledge about survival in YOD and provide support for longer survival in persons with YOD compared to LOD. This underlines the need for long lasting support systems that are focused on the needs of these patients.

An indication was found for a different survival in the three main subtypes of YOD, with $\mathrm{AD}$ participants having the shortest survival. Therefore, an accurate diagnosis is relevant to take into account concerning prognosis.

Distress and uncertainty perhaps can be diminished by using our study outcomes when informing individuals with YOD and their families. Nevertheless, lost life years, both absolute and relative, will have an impact on the future perspective of these persons and their families. This burden is added to the uncertainty about prognosis and life expectancy, after the struggle of getting a proper diagnosis (Baptista et al., 2016; van Vliet et al., 2011). Our findings are perhaps not as negative as often thought, but they address the reason for intensive care support as long as dementia is only treatable symptomatically.

A recommendation for future research might be to include disease severity at the time of diagnosis in studies on survival in patients with YOD. Death certificates or interviews with caregivers can help to better clarify our understanding of the relationship between an early death and the course of the dementia. Furthermore, given the different findings about survival in young persons with FTD, survival in this dementia subgroup also needs further investigation.

\section{Funding}

This research was supported with grants from the Dutch Alzheimer's Foundation, Bunnik, the Wever Care Group, Tilburg, and from the Florence Care Group, the Hague, all of which in the Netherlands.

\section{Conflicts of interest}

None.

\section{Description of authors' roles}

A. Gerritsen designed the study, collected parts of the data, performed the analyses and wrote the paper. C. Bakker designed the study, collected parts of the data and co-wrote the paper. J. Millenaar 
collected parts of the data and critically reviewed the paper. R. Koopmans designed the study and critically reviewed the paper. F. Verhey, Y. Pijnenburg and $M$. de Vugt advised about the study design and critically reviewed the paper.

\section{Acknowledgments}

Yvette Daniels and Deliane van Vliet participated in data collection, Hans Bor gave statistical advices.

\section{References}

Addona, V., Atherton, J. and Wolfson, D. B. (2012). Testing the assumptions for the analysis of survival data arising from a prevalent cohort study with follow-up. The International fournal of Biostatistics 8, 22.

Armstrong, R. A. (2014). Factors determining disease duration in Alzheimer's disease: a postmortem study of 103 cases using the Kaplan-Meier estimator and Cox regression. BioMed Research International, 2014, 623487.

Atkins, E. R., Bulsara, M. K. and Panegyres, P. K. (2012). The natural history of early-onset dementia: the Artemis Project. BMF Open, 2, e001764.

Baptista, M. A. et al. (2016). Quality of life in young onset dementia: an updated systematic review. Trends Psychiatry Psychother, 38, 6-13.

Barclay, L. L., Zemcov, A., Blass, J. P. and McDowell, F. H. (1985a). Factors associated with duration of survival in Alzheimer's disease. Biological Psychiatry, 20, 86-93.

Barclay, L. L., Zemcov, A., Blass, J. P. and Sansone, J. (1985b). Survival in Alzheimer's disease and vascular dementias. Neurology, 35, 834-840.

Breslow, N. (1974). Covariance analysis of censored survival data. Biometrics, 30, 89-99.

Brodaty, H., Seeher, K. and Gibson, L. (2012). Dementia time to death: a systematic literature review on survival time and years of life lost in people with dementia. International Psychogeriatrics, 24, 1034-1045.

Carter, J. E., Oyebode, J. R. and Koopmans, R. (2018). Young-onset dementia and the need for specialist care: a national and international perspective. Aging and Mental Health, 22, 468-473.

Chang, K. J. et al. (2017). Mortality risk after diagnosis of early-onset Alzheimer's disease versus late-onset Alzheimer's disease: a propensity score matching analysis. Fournal of Alzheimer's Disease, 56, 1341-1348.

Crowley, J. and Breslow, N. (1984). Statistical analysis of survival data. Annual Review of Public Health, 5, 385-411.

Diehl-Schmid, J., Pohl, C., Perneczky, R., Hartmann, J., Forstl, H. and Kurz, A. (2007). [Initial symptoms, survival and causes of death in 115 patients with frontotemporal lobar degeneration]. Fortschritte der Neurologie-Psychiatrie, 75, 708-713.

Erkinjuntti, T. (1994). Clinical criteria for vascular dementia: the NINDS-AIREN criteria. Dementia, 5, 189-192.

First, M. B., Frances, A. and Pincus, H. A. (2002). DSM$I V-T R$, handbook of differential diagnosis. Arlington, VA: American Psychiatric Publishing, Inc.
Garcia-Ptacek, S., Farahmand, B., Kareholt, I., Religa, D., Cuadrado, M. L. and Eriksdotter, M. (2014). Mortality risk after dementia diagnosis by dementia type and underlying factors: a cohort of 15, 209 patients based on the Swedish Dementia Registry. Fournal of Alzheimer's Disease, 41, 467-477.

Gerritsen, A. A. et al. (2016). Prevalence of comorbidity in patients with young-onset Alzheimer disease compared with late-onset: a comparative cohort study. fournal of the American Medical Directors Association, 17, 318-323.

Gerritsen, A. A. J. et al. (2018). The progression of dementia and cognitive decline in a Dutch 2-Year cohort study of people with young-onset dementia. Fournal of Alzheimer's Disease, 63, 343-351.

Gronning, H., Rahmani, A., Gyllenborg, J., Dessau, R. B. and Hogh, P. (2012). Does Alzheimer's disease with early onset progress faster than with late onset? A case-control study of clinical progression and cerebrospinal fluid biomarkers. Dementia and Geriatric Cognitive Disorders, 33, 111-117.

Hodges, J. R., Davies, R., Xuereb, J., Kril, J. and Halliday, G. (2003). Survival in frontotemporal dementia. Neurology, 61, 349-354.

Holland, D., Desikan, R. S., Dale, A. M., McEvoy, L. K. and Alzheimer's Disease Neuroimaging, I. (2012). Rates of decline in Alzheimer disease decrease with age. PLoS One, 7, e42325.

Ientile, L. et al. (2013). Survival rate in patients affected by dementia followed by memory clinics (UVA) in Italy. fournal of Alzheimer's Disease, 36, 303-309.

Jacobs, D. et al. (1994). Age at onset of Alzheimer's disease: relation to pattern of cognitive dysfunction and rate of decline. Neurology, 44, 1215-1220.

Jost, B. C. and Grossberg, G. T. (1995). The natural history of Alzheimer's disease: a brain bank study. Fournal of the American Geriatrics Society, 43, 1248-1255.

Kane, R. L., Shamliyan, T., Talley, K. and Pacala, J. (2012). The association between geriatric syndromes and survival. Fournal of the American Geriatrics Society, 60, 896-904.

Kaplan, E. L. and Meier, P. (1958). Nonparametricestimation from incomplete observations. Fournal of the American Statistical Association, 53, 457-481.

Kay, D. W., Forster, D. P. and Newens, A. J. (2000). Long-term survival, place of death, and death certification in clinically diagnosed pre-senile dementia in northern England. Follow-up after 8-12 years. British fournal of Psychiatry, 177, 156-162.

Knopman, D. S., Rocca, W. A., Cha, R. H., Edland, S. D. and Kokmen, E. (2003). Survival study of vascular dementia in Rochester, Minnesota. Archives of Neurology, 60, 85-90.

Koedam, E. L. et al. (2008). Early-onset dementia is associated with higher mortality. Dementia and Geriatric Cognitive Disorders, 26, 147-152.

Lee, M. and Chodosh, J. (2009). Dementia and life expectancy: what do we know? Fournal of the American Medical Directors Association, 10, 466-471.

McGonigal, G., McQuade, C. A., Thomas, B. M. and Whalley, L. J. (1992). Survival in presenile Alzheimer's and multi-infarct dementias. Neuroepidemiology, 11, 121-126. 
McKhann, G., Drachman, D., Folstein, M., Katzman, R., Price, D. and Stadlan, E. M. (1984). Clinical diagnosis of Alzheimer's disease: report of the NINCDS-ADRDA Work Group under the auspices of Department of Health and Human Services Task Force on Alzheimer's Disease. Neurology, 34, 939-944.

Milieu, R. (2018). Volksgezondheid Toekomst Verkenning 2018: Een gezond vooruitzicht. (Rijksinstituut voor Volksgezondheid en Milieu. Dutch National Institute for Public Health and the Environment.) Bilthoven. Available at: https://www.rivm.nl/bibliotheek/rapporten/2018-0030 .pdf; last accessed August 2018.

Neary, D. et al. (1998). Frontotemporal lobar degeneration: a consensus on clinical diagnostic criteria. Neurology, 51, 1546-1554.

Panegyres, P. K. and Chen, H. Y. (2013). Differences between early and late onset Alzheimer's disease. American Fournal of Neurodegenerative Disease, 2, 300-306.

Perrault, A., Wolfson, C., Egan, M., Rockwood, K. and Hogan, D. B. (2002). Prognostic factors for functional independence in older adults with mild dementia: results from the Canadian study of health and aging. Alzheimer Disease and Associated Disorders, 16, 239-247.

Prince, M., Wimo, A., Guerchet, M., Ali, G.C., Wu, Y.T., Prina, M (2016). World Alzheimer Report 2016. London: Alzheimer's Disease International.

Rait, G., Walters, K., Bottomley, C., Petersen, I., Iliffe, S. and Nazareth, I. (2010). Survival of people with clinical diagnosis of dementia in primary care: cohort study. BMF, 341, c3584.

Rasmusson, D. X., Carson, K. A., Brookmeyer, R., Kawas, C. and Brandt, J. (1996). Predicting rate of cognitive decline in probable Alzheimer's disease. Brain and Cognition, 31, 133-147.

Reisberg, B., Ferris, S. H., de Leon, M. J. and Crook, T. (1982). The Global Deterioration Scale for assessment of primary degenerative dementia. The American fournal of Psychiatry, 139, 1136-1139.

Roberson, E. D. et al. (2005). Frontotemporal dementia progresses to death faster than Alzheimer disease. Neurology, 65, 719-725.

Rossor, M. N., Fox, N. C., Mummery, C. J., Schott, J. M. and Warren, J. D. (2010). The diagnosis of young-onset dementia. Lancet Neurology, 9, 793-806.

Stanley, K. and Walker, Z. (2014). Do patients with young onset Alzheimer's disease deteriorate faster than those with late onset Alzheimer's disease? A review of the literature. International Psychogeriatrics, 26, 1945-1953.
Statline, Statistics Netherlands' database. (2017a). Available at https://opendata.cbs.nl/statline/\#/CBS/nl/ dataset/37360ned/table?ts $=1543837224473$; last accessed 3 December 2018.

Statline, Statistics Netherlands' database. (2017b). Sterftekansen naar leeftijd, geslacht. Available at https://opendata.cbs.nl/statline/\#/CBS/nl/dataset/ 37360ned/table?ts $=1543840176015$; last accessed 3 December 2018.

Stokes, L., Combes, H. and Stokes, G. (2015). The dementia diagnosis: a literature review of information, understanding, and attributions. Psychogeriatrics, 15, 218-225.

Todd, S., Barr, S., Roberts, M. and Passmore, A. P. (2013). Survival in dementia and predictors of mortality: a review. International fournal of Geriatric Psychiatry, 28, 1109-1124.

Tschanz, J. T. et al. (2004). Dementia: the leading predictor of death in a defined elderly population: the Cache County Study. Neurology, 62, 1156-1162.

Ueki, A., Shinjo, H., Shimode, H., Nakajima, T. and Morita, Y. (2001). Factors associated with mortality in patients with early-onset Alzheimer's disease: a five-year longitudinal study. International fournal of Geriatric Psychiatry, 16, 810-815.

van der Vlies, A. E., Koedam, E. L., Pijnenburg, Y. A., Twisk, J. W., Scheltens, P. and van der Flier, W. M. (2009). Most rapid cognitive decline in APOE epsilon4 negative Alzheimer's disease with early onset. Psychological Medicine, 39, 1907-1911.

Vansteelandt, S., Dukes, O. and Martinussen, T. (2017). Survivor bias in Mendelian randomization analysis. Biostatistics, 19, 426-443.

van Vliet, D., Bakker, C., Koopmans, R. T., Vernooij-Dassen, M. J., Verhey, F. R. and de Vugt, M. E. (2010). Research protocol of the NeedYD-study (Needs in Young onset Dementia): a prospective cohort study on the needs and course of early onset dementia. BMC Geriatrics, 10, 13.

van Vliet, D. et al. (2011). Caregivers' perspectives on the pre-diagnostic period in early onset dementia: a long and winding road. International Psychogeriatrics, 23, 1393-1404.

World Health Organization (2012). Dementia: A Public Health Priority. Geneva: World Health Organization.

World Health Organization (2014). International classification of diseases, 10th revison (ICD-10) online (2014 version). Available at: https://www.who.int/ classifications/icd/icdonlineversions/en. 